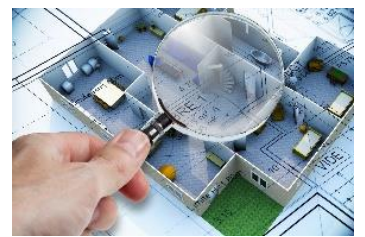

\title{
Analysis of price differences that occurred in the years 2016-2020 between the actual implementation of construction projects and the data presented by the price publisher Sekocenbud
}

\author{
Konrad SZCZEPANIK ${ }^{1}$ (ORCID ID: 0000-0001-6369-5098) \\ ${ }^{1}$ Contract Advisory Services Sp. z o. o., 98/7 Pańska Str., 00-837 Warsaw, Poland \\ corresponding author: konrad.szczepanik@caservices.pl
}

\begin{abstract}
The analysis aims to demonstrate extraordinary price changes for all construction sectors (road, rail and cubature) between 2016 and 2020. The analysis shows how the forecast looked like in the Sekocenbud publication for Q1 2016 and how it reflected future prices. Additionally, prices published in Sekocenbud every quarter of the period mentioned above are included and compared in the analysis. The forecast that is presented in the Sekocenbud publication shows the projected prices for the next 2 years, to get the forecast for the rest of the forecast period a trend line was used. Then all the data compared were placed on charts and the differences were described.
\end{abstract}

Keywords: forecast, prices, cost calculation, extraordinary, increase.

Access to the content of the article is only on the bases of the Creative Commons licence CC BY-NC-ND 4.0

Please, quote this article as follows:

Szczepanik K., Analysis of price differences that occurred in the years 2016-2020 between the actual implementation of construction projects and the data presented by the price publisher Sekocenbud, Engineering Expert, p. 35-43, No. 1, 2020, DOI: 10.37105/enex.2020.1.1.05

\section{Introduction}

In the construction industry, the last four years have been a period of very dynamic economic growth, preceding a crisis caused by the coronavirus pandemic, which has led to an economic slowdown. This is best illustrated by the negative GDP result for the second quarter of year 2020 $(-8.9 \%)$, which in the previous years had been growing continuously: $2016-2.8 \%, 2017-4.8 \%, 2018$ $-5.1 \%, 2019-4.0 \%$.

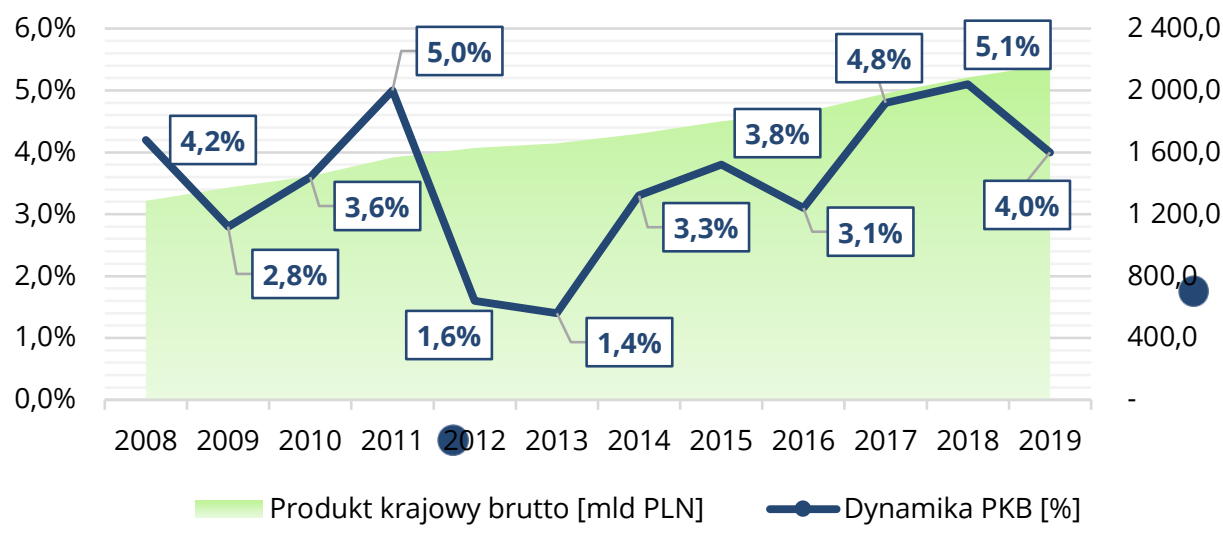

Fig. 1. The value and pace of GDP growth, prepared on the basis of data provided by the Central Statistical Office. 
In Poland, as the employment rate grew, the level of unemployment reached an unprecedented low level of $5.2 \%$ at the end of year 2019. In the period of dynamic economic growth, the construction industry - particularly the segment of infrastructural investments - faces a great challenge of the investment duration. It usually takes several years to complete. The final price of building production for these investments is specified in the bids placed in public tenders and agreed in the contracts with employers. The price is fixed throughout the entire contract term, most often expressed as a flat rate. Therefore, the prices for construction works were often calculated several years earlier on the basis of price lists available at the time and the market conditions, and they fail to take into account the changes that occurred in the course of performance of the contract.

In the recent years, there was a substantial change in the cost of acquisition of factors of production (L-labor, M - material, E-equipment), which could not have been predicted by anyone. This is proven by the number of public tenders (GDDKiA - General Directorate for Roads and Motorways - and PKP PLK - Polish National Railway, Polish Railway Lines), in which the investor's budget has been exceeded.
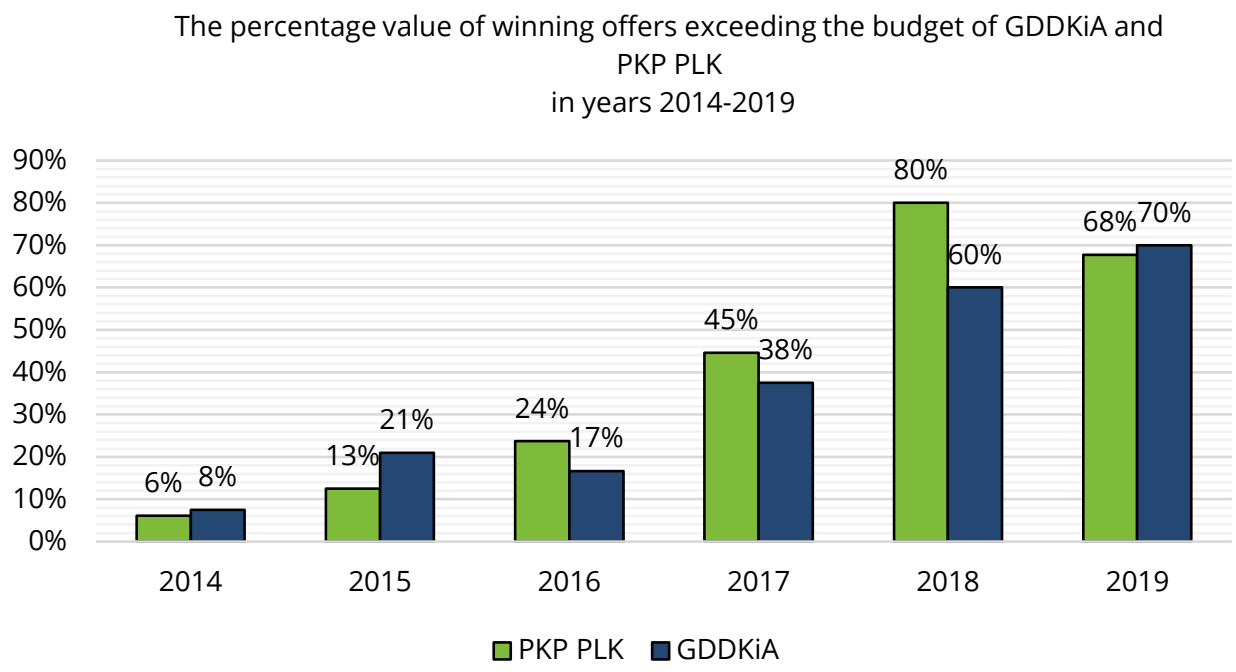

Fig. 2. The percentage share of selected bids exceeding the budget of GDDKiA in years 2014-2019, prepared by CAS.

Starting from year 2016, the number of bids exceeding the budget of the public investor has been growing very quickly In the case of PKP PLK, in year 2018, the number of bids, which won the tenders and exceeded the budget of the employer reached $80 \%$. This means that only one out of five public contracts concluded by PKP PLK were within the limits of the budget of the employer. As for the General Directorate of Road and Motorways, a record-breaking number of bids placed in tenders, which exceeded the budget, was recorded in year 2019 - in only 3 out of 10 public tenders, the winner was able to comply with the financial plan of the investor.

Over the years, changeability of costs and demand for construction services were neglected in the official narration, and economic indicators included in popular publishers, such as Sekocenbud or Intercenbud, turned out to be inadequate and failed to catch up with the real changes taking place on the market.

\section{A literature review}

In the introduction to the section on forecast price changes in the construction industry, the Sekocenbud bulletin of aggregated indicator indicates that forecasting of economic phenomena is one of the methods of minimizing risk, making it possible to gain an advantage over other market participants. The reason for publication of forecasts is to take into account inflation or deflation in 
negotiations and determination of consideration amounts for long-term investments. However, until year 2018, the discrepancies between the actual conditions and forecasts went unnoticed.

"The forecasts obtained may be considered to be very accurate, which is proven by high values of determination coefficients and low average forecast errors throughout the analyzed period. The relative average forecast errors expressed as percentages indicate that in most cases, the forecast price changes in the verification period differ from the real values by less than $1 \%$. Such low measure values make it possible to recognize the forecasts as acceptable" [1].

In year 2018, the methodology used to calculate prices in the construction industry was modified in response to market needs, which led to increasing of the forecast values for years 2018-2020; it was thus concluded that "their further increase was expected in year 2019 and 2020" [2]. At the same time, in the following edition, it was stated that "Substantial changes in the pace of the trends observed (high trend value increases over time) have led to the decision to apply modified models to develop forecasts. ... If we want deductions concerning changes in prices in construction to be sufficiently certain, we need to update not only the data used in the models, but also the models themselves. The need to update the models was recognized for the majority of the series analyzed" [3]. This means that data published until mid-2017, in which publishers presented forecasts that did not exceed the inflation level, were considered to be very accurate; only after it was noticed that the forecast presented in the publisher and the real prices differed substantially, an adjustment was made in the methodology of calculation of future prices in the construction industry.

\section{The research methods used}

The analysis presents differences between the data published from widely available price publishers for the construction industry and the real data, developed on the basis of many grand scale road, rail and cubature infrastructure projects. The following data was used in the analysis comparing the LME values and overall changes in prices of facilities in construction from Q1 of year 2016 until Q1 of year 2020:

1) ZWW $1 / 2016$ as the baseline values and a forecast for the 4 coming years;

2) The collected ZWW indicators, published in years 2016-2020;

3) Real values of changes in contracts [4].

For the data obtained from ZWW, we have a forecast provided for the following 2 years. For the purpose of the analysis, it was necessary to obtain a forecast for the next 4 years. We obtained it on the basis of a trend line, which indicates the direction of changes in data using a straight line on the chart. In order for the obtained trend line to reflect the forecast based on our data, we shifted it to the last available value, that is, Q1 2018. Presented below is the exact data for the determined trend line adjustment and the method of its determination, where the adjustment value "c" is referred to as:

$$
c=y-x \cdot i
$$

where:

$\mathrm{c}$ - adjustment value of the trend line;

$\mathrm{y}$ - indicator value for Q1 2018;

$\mathrm{i}$ - quarter number, in this case, 9.

Table 1. Determination of the optimum trend line.

\begin{tabular}{|l|c|c|c|c|}
\cline { 2 - 5 } \multicolumn{1}{c|}{} & \multicolumn{4}{c|}{ Determination of the optimum trend line } \\
\cline { 2 - 5 } \multicolumn{1}{c|}{} & Trend line formula & Trend line formula - adjustment \\
\hline Parameter: & $\mathrm{x}$ & $\mathrm{c}$ & $\mathrm{x}$ & $\mathrm{c}$ \\
\hline Construction in total & 0.1061 & 102.18 & 0.1061 & 101.6251 \\
\hline
\end{tabular}




\begin{tabular}{|l|c|c|c|c|}
\cline { 2 - 5 } \multicolumn{1}{c|}{} & \multicolumn{4}{c|}{ Determination of the optimum trend line } \\
\cline { 2 - 5 } \multicolumn{1}{c|}{} & Trend line formula & Trend line formula - adjustment \\
\hline Labor cost rate & -0.4757 & 103.14 & -0.4757 & 103.8913 \\
\hline Building material & 0.2278 & 100.37 & 0.2278 & 99.7098 \\
\hline Equipment operation & 0.1095 & 101.7 & 0.1095 & 101.4145 \\
\hline
\end{tabular}

The real values of changes in contracts have been developed as the "Report on costs in the construction industry 2016-2020" by CAS company, which operates on the market of consulting services for the construction sector. The report was prepared on the basis of 38 very big projects of contractual value nearing net PLN 6 billion. The sector structure is as follows:

- 14 projects from the road sector,

- 7 projects from the railway sector,

-17 projects from the cubature sector.

The data was collected and then plotted in a single chart. In addition, a percentage change has been calculated for each subsequent year in relation to year 2016. The values presented in the chart refer to Q1 2015.

\section{Research results and discussion}

The change in years 2016-2020 was undoubtedly high and unpredictable, which is illustrated by the overall increase in prices in the construction industry (the average price increase in housing apartment buildings, public utility buildings, production and commercial facilities, warehouses, roads, bridges and viaducts), which amounted to $29.4 \%$ in the period of 4 years. The forecast price increase published by Sekocenbud in ZWW 1/2016 amounted to 3.43\%, that is, an increase of more than 8 times less.

Undoubtedly, the most surprising was the change in the estimated labor cost rate for general construction works, which in the period of 4 years increased by more than $41 \%$, while even a decrease in the price of $4.2 \%$ was expected. For the sake of comparison, the difference in the change of real prices and forecast-based prices for building materials is $25.85 \%$, and for construction equipment it is $14.35 \%$.

\section{Presentation of analyses}

\subsection{A change in the value of Labor in years 2016-2020}

Presented below is a percentage change in the labor cost rate in relation to Q1 2015 for the three groups discussed.

Table 2. Percentage change for labor cost rate in relation to year 2015.

\begin{tabular}{|c|c|c|c|c|}
\hline & & \multicolumn{3}{|c|}{ Percentage change in relation to Q1 2015 - 100} \\
\hline Parameter: & Year & $\begin{array}{l}\text { According to } \\
\text { ZWW Sekocen- } \\
\text { bud }\end{array}$ & Forecast of Q1 2016 & $\begin{array}{l}\text { According to real increases for } \\
\text { Contracts }\end{array}$ \\
\hline \multirow{5}{*}{ Labor cost rate } & 2016 & $3,20 \%$ & $3,20 \%$ & $2,41 \%$ \\
\hline & 2017 & $7,30 \%$ & $0,08 \%$ & $7,01 \%$ \\
\hline & 2018 & $12,30 \%$ & $-0,39 \%$ & $28,99 \%$ \\
\hline & 2019 & $36,10 \%$ & $-2,29 \%$ & $44,57 \%$ \\
\hline & 2020 & $53,10 \%$ & $-4,20 \%$ & $41,14 \%$ \\
\hline
\end{tabular}


The chart below presents correlations in individual quarters for the labor cost rate.

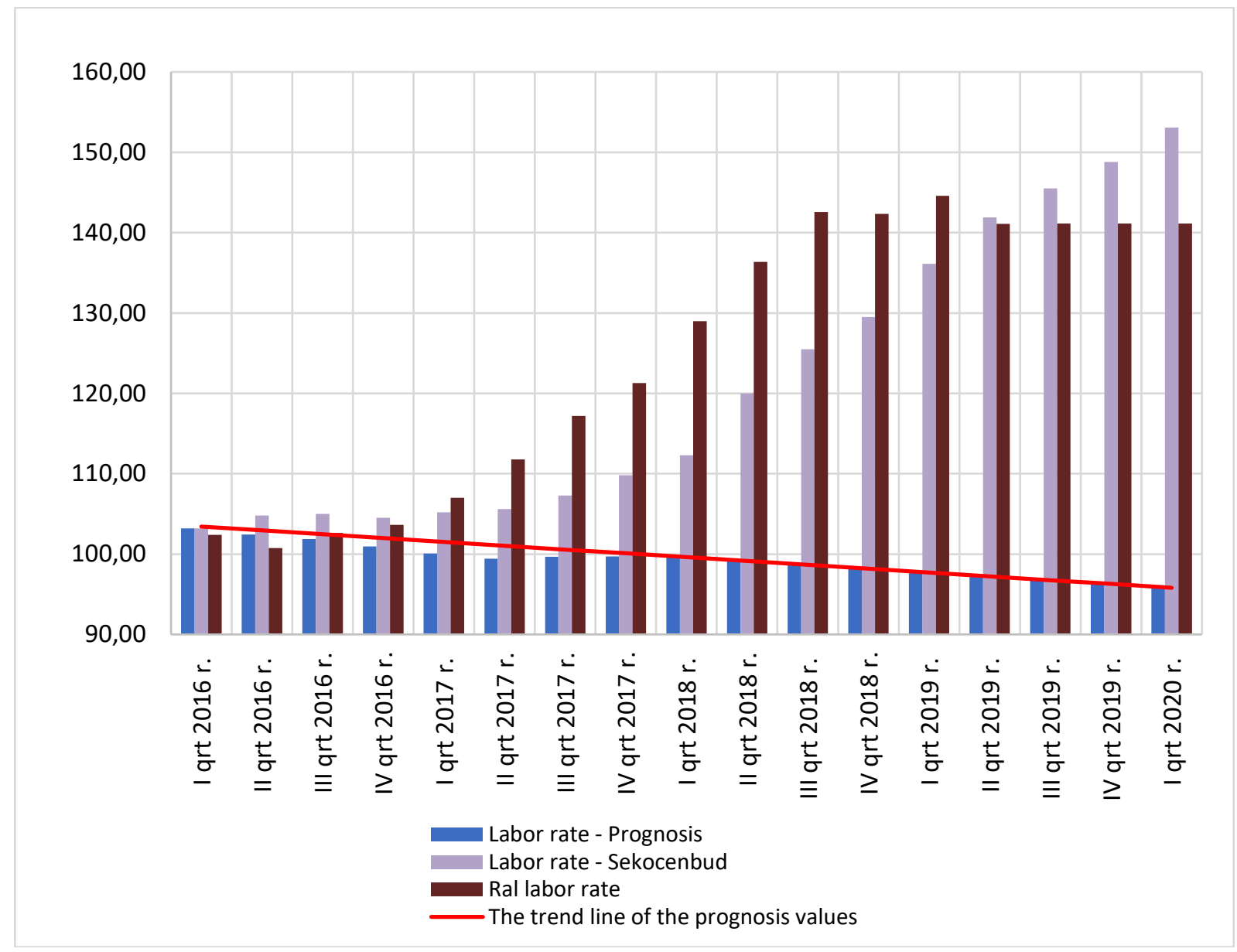

Fig. 3. The change in the labor cost rate in individual quarters from Q1 2016 until Q1 2020.

In year 2016, publishers projected a decrease in the labor cost rates in the coming years. Subsequent publications illustrate a slow increase in this value, while at the end of the first / end of the second quarter of year 2018, there is a visible sudden increase in the labor cost rate and an acceleration of the increase trend, which remained dynamic until the end of the period under analysis.

The increase in real labor cost rates was observed in mid-2017 - more than six months before we obtained this information from the Sekocenbud publisher. On the other hand, in the second half of year 2018 , there is a slowdown of the growth trend, which even comes to a stop as the prices for this indicator begin to stabilize.

The difference between the forecast and the real price in Q1 2020 is as much as 57.3\%. A substantial, although slightly lower change was recorded between the forecast and real value in the same period $-45.34 \%$.

\subsection{A change in the value of building materials in years $2016-2020$}

Presented below is a percentage change in the prices of building materials in relation to Q1 2015 for the three groups discussed. 
Table 3. Percentage change for the prices of building materials in relation to year 2015.

\begin{tabular}{|c|c|c|c|c|}
\cline { 3 - 5 } \multicolumn{2}{c|}{} & \multicolumn{3}{c|}{ Percentage change in relation to Q1 2015 - 100 } \\
\hline \multirow{4}{*}{ Parameter } & Year & $\begin{array}{c}\text { According to ZWW } \\
\text { Sekocenbud }\end{array}$ & Forecast of Q1 2016 & According to real contracts \\
\hline \multirow{4}{*}{ Building material } & 2016 & $0,30 \%$ & $0,30 \%$ & $-0,67 \%$ \\
\cline { 2 - 5 } & 2017 & $-0,80 \%$ & $1,66 \%$ & $5,21 \%$ \\
\cline { 2 - 5 } & 2018 & $2,70 \%$ & $1,76 \%$ & $17,24 \%$ \\
\cline { 2 - 5 } & 2019 & $9,60 \%$ & $2,67 \%$ & $25,32 \%$ \\
\cline { 2 - 5 } & 2020 & $15,30 \%$ & $3,58 \%$ & $29,43 \%$ \\
\hline
\end{tabular}

The chart below presents correlations in individual quarters for building materials.

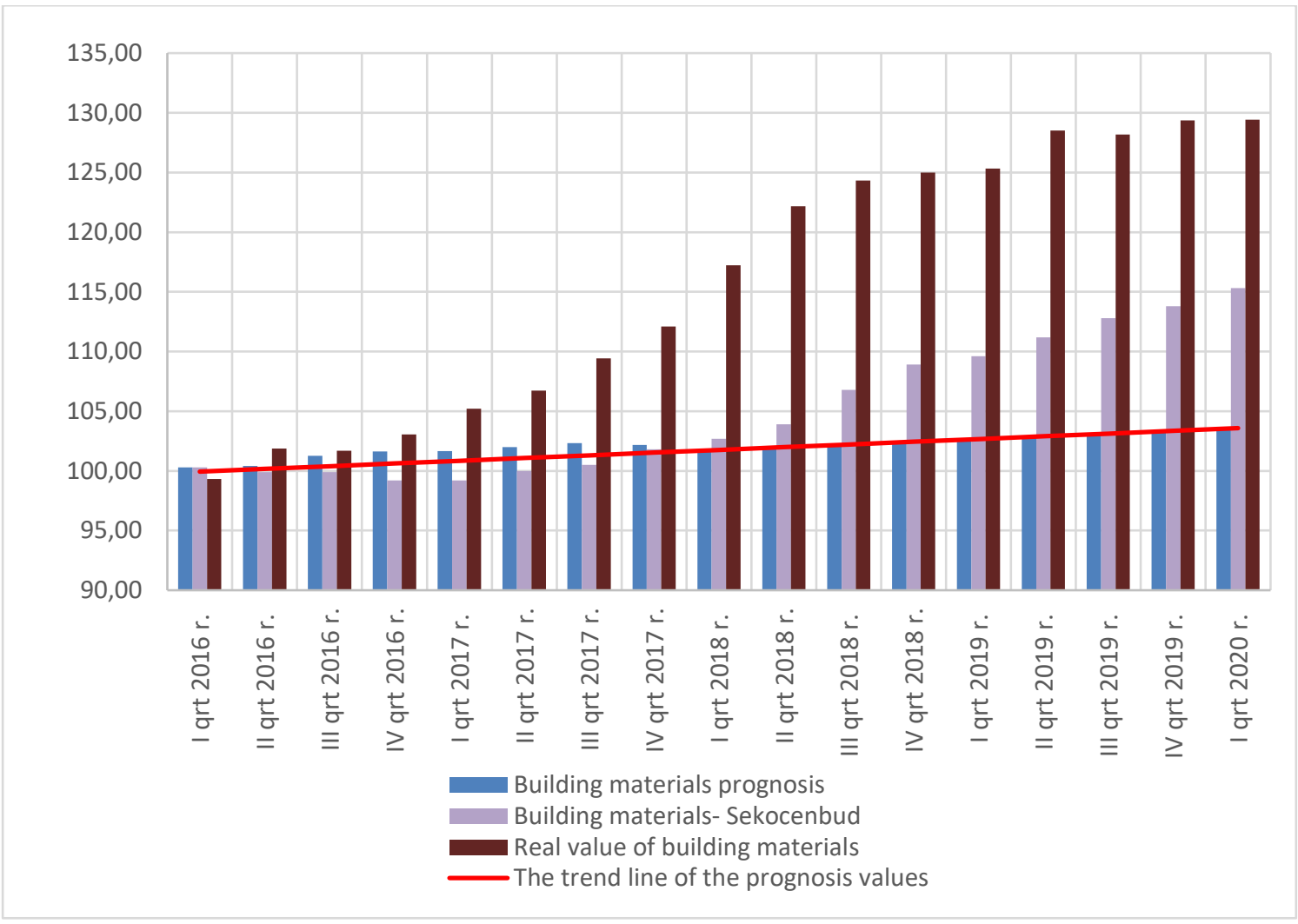

Fig. 4. The change in building material prices in individual quarters from Q1 2016 until Q1 2020.

The prices of building materials kept increasing from the start of year 2016. According to the forecast based on Q1 2016, the expected growth in the period of five years was 3.58\% in reference to the baseline value (Q1 2015). Assuming a constant percentage change between individual years, we obtain an increase by $0.706 \%$ year on year. It is consistent with the data of Sekocenbud until Q1 of 2018; however, in the following two years, the difference in the price increase is $11.72 \%$.

The real change in the prices of construction equipment presented in the chart illustrates a sudden increase in prices as early as at the beginning of year 2017, whereas in the same period, the Sekocenbud publications depict a slow growth trend, which accelerates 1 to 1.5 years later than it did in reality. The most substantial difference between the data published by Sekocenbud and the real values is observed in Q2 2018, amounting to $18.26 \%$. The ultimate difference between the Sekocenbud publication and the original forecast from year 2016 is $11.72 \%$, while the gap in relation to real values is 25.85 percentage points. 
Analysis of price differences that occurred in the years 2016-2020 between the actual implementation of construction projects and the data presented by the price publisher Sekocenbud

\subsection{A change in the value of costs of construction equipment operation in years 2016-2020}

Presented below is a percentage change in the prices of operation of construction equipment in relation to Q1 2015 for the three groups discussed.

Table 4. Percentage change for prices of construction equipment in relation to year 2015.

\begin{tabular}{|c|c|c|c|c|}
\cline { 3 - 5 } \multicolumn{2}{c|}{} & \multicolumn{3}{c|}{ A percentage change in relation to Q1 2015 - 100 } \\
\hline \multirow{3}{*}{ Parameter: } & Year & $\begin{array}{c}\text { According to ZWW Se- } \\
\text { kocenbud }\end{array}$ & Forecast of Q1 2016 & According to real contracts \\
\hline \multirow{3}{*}{$\begin{array}{c}\text { Equipment } \\
\text { operation }\end{array}$} & 2016 & $1,50 \%$ & $1,50 \%$ & $-1,37 \%$ \\
\cline { 2 - 5 } & 2017 & $2,00 \%$ & $2,00 \%$ & $6,74 \%$ \\
\cline { 2 - 5 } & 2018 & $4,20 \%$ & $2,40 \%$ & $16,92 \%$ \\
\cline { 2 - 5 } & 2019 & $8,80 \%$ & $2,84 \%$ & $17,69 \%$ \\
\hline
\end{tabular}

The chart below presents correlations in individual quarters for construction equipment.

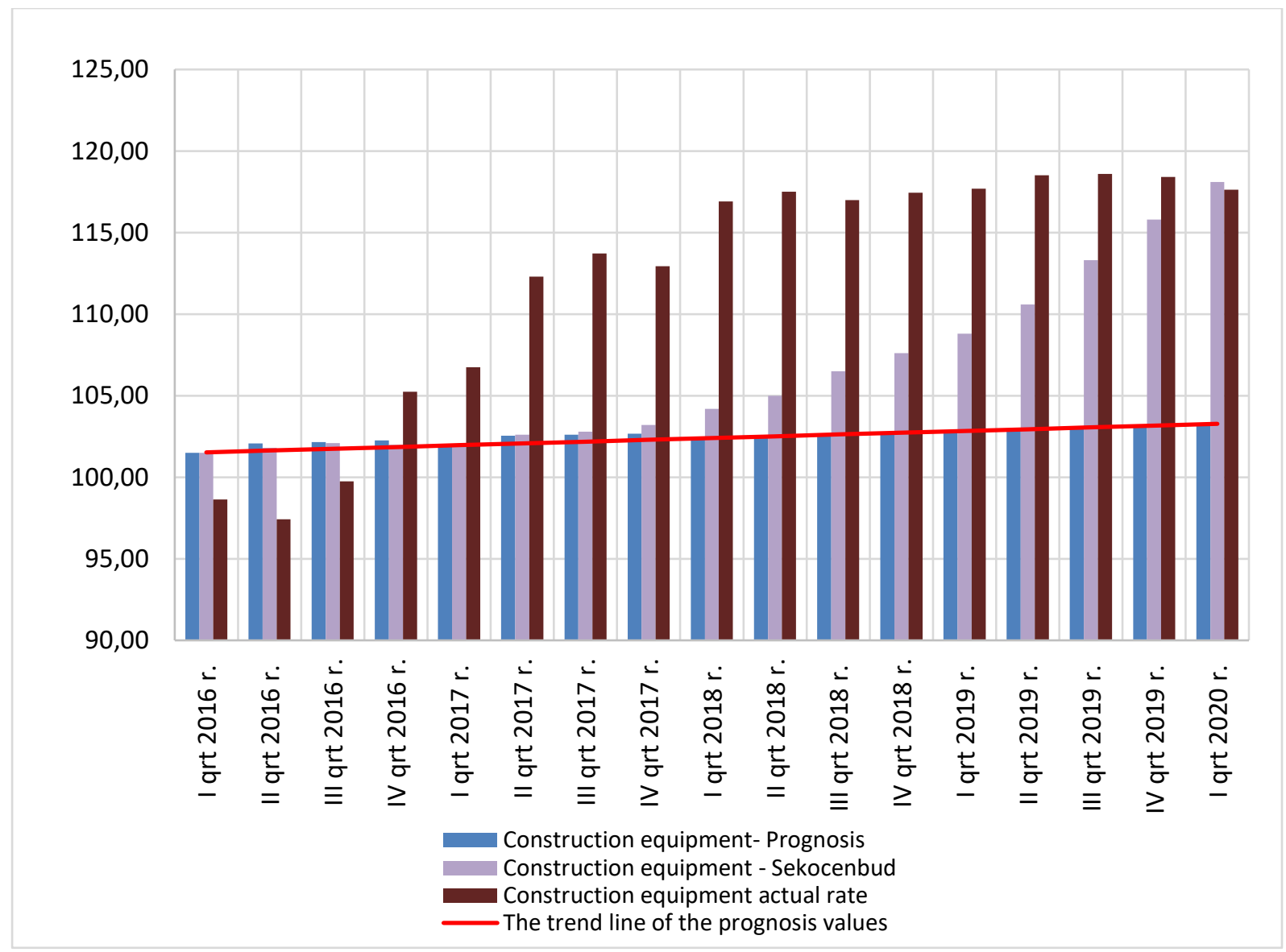

Fig. 5. The change in prices of construction materials in individual quarters from Q1 2016 until Q1 2020.

In the forecast for year 2016, there was a growth tendency, amounting to $3.28 \%$ in the five-year period. On the other hand, according to Sekocenbud publications, this difference amounts to $17.62 \%$, which, in general, is close to the real cost increase in the analyzed projects, which amounted to $18.1 \%$. The difference between the forecast for year 2016 and the value of the indicator in year 2020 was 
14.34 percentage points, which constitutes the smallest difference among all of the values of LME factors of production. As in the previous charts, the delay in the growth trend between the real and published values is more than one year. The real prices stabilized and stopped growing from the beginning of year 2019, and the difference in price in relation to Q1 2020 was $-0.07 \%$, which can be considered to be a statistical error; therefore, it can be assumed that the price remained unchanged throughout the year.

\subsection{A change in the average value of prices in the construction industry in general in years 2016-2020}

Presented below is a percentage change of prices in the construction industry in relation to Q1 2015 for the three groups examined.

Table 5. Percentage change for prices of construction equipment in relation to year 2015.

\begin{tabular}{|c|c|c|c|c|}
\cline { 2 - 5 } \multicolumn{2}{c|}{} & \multicolumn{3}{c|}{ A percentage change in relation to Q1 2015 - 100 } \\
\hline \multirow{4}{*}{ Parameter: } & Year & $\begin{array}{c}\text { According to } \\
\text { ZWW Sekocenbud }\end{array}$ & $\begin{array}{c}\text { Forecast of Q1 } \\
2016\end{array}$ & According to real contracts \\
\hline \multirow{4}{*}{$\begin{array}{c}\text { Construction in } \\
\text { total }\end{array}$} & 2016 & $1,68 \%$ & $1,68 \%$ & $-0,43 \%$ \\
\cline { 2 - 5 } & 2017 & $3,14 \%$ & $2,88 \%$ & $5,68 \%$ \\
\cline { 2 - 5 } & 2018 & $7,68 \%$ & $2,58 \%$ & $19,24 \%$ \\
\cline { 2 - 5 } & 2019 & $21,64 \%$ & $3,00 \%$ & $27,11 \%$ \\
\cline { 2 - 5 } & 2020 & $30,70 \%$ & $3,43 \%$ & $29,41 \%$ \\
\hline
\end{tabular}

The chart below presents correlations in individual quarters for construction equipment.

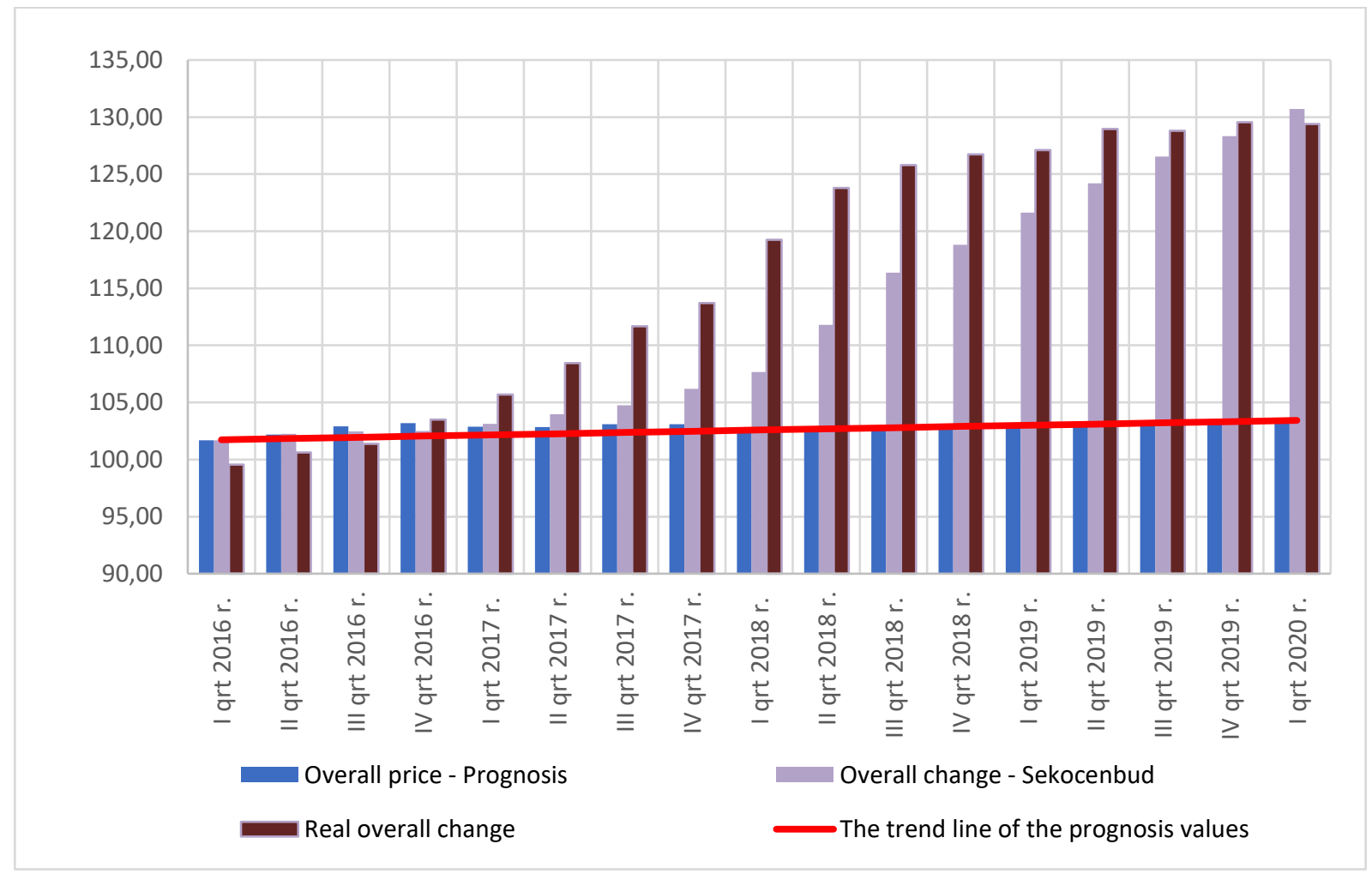

Fig. 6. The change in prices in the construction industry in individual quarters from Q1 2016 until Q1 2020. 
The forecast general increase in prices in the construction industry was determined for the five-year period at the level of $3.43 \%$, which was exceeded by the real increase in prices as early as at the beginning of year 2017. Ultimately, after five years, the difference between the forecast values and prices based on real projects is 25.96 percentage points, and between the Sekocenbud indicators, it is 27.27 percentage points. The difference in values between data published by Sekocenbud and the real changes in prices in Q1 2020 is $1.31 \%$. The prices quoted in the publisher are delayed by about six months in relation to the real values from construction contracts. Year 2019 seemed almost unchangeable for the real prices in the construction industry. The growth trend, as in the case of LME, was substantially slowed down.

\section{Conclusions}

According to publication ZWW 1/2020, the prices in the coming years will continue a dynamic growth, which will even accelerate. The unexpected pandemic, which affected all sectors of economy, will undoubtedly exert a significant influence on future prices, not only in the construction industry. According to the above analysis for years 2016-2020, the indicators based on publications fail to reflect the actual circumstances as they are based on historic data. On the average, they are delayed in relation to the market and real prices by about 1.5 year. Due to the present global situation, the prices in the coming months and years may be equally changeable and unpredictable.

\section{Acknowledgements}

I would like to thank CAS Sp. z o.o. for disclosing the analysis "Report on costs in the construction industry 2016-2020", which turned out to provide invaluable assistance in development of the analysis. In particular, I would like to thank Mr. Maciej Kajrukszto and Mr. Jan Gandziarowski for their substantive advice and support in writing of this article.

\section{Bibliography}

[1] ZWW 3/2017

[2] ZWW 3/2018

[3] ZWW 4/2018

[4] Report on costs in the construction industry 2016-2020, CAS Sp. z o.o. 